\title{
The Pharmacogenetics of Tacrolimus in Corticosteroid-Sparse Pediatric and Adult Kidney Transplant Recipients
}

\author{
Mads Juul Madsen ${ }^{1} \cdot$ Troels K. Bergmann ${ }^{2,3} \cdot \operatorname{Kim~Brøsen}^{4} \cdot$ Helle Charlotte Thiesson ${ }^{1}$
}

Published online: 22 February 2017

(c) The Author(s) 2017. This article is published with open access at Springerlink.com

\begin{abstract}
Introduction Tacrolimus is a calcineurin inhibitor used as an immunosuppressant drug in solid organ transplantation, and is mainly metabolized by cytochrome $\mathrm{P} 450$ (CYP) 3A4 and CYP3A5. Studies have shown an association between the CYP3A5 genotype and tacrolimus doseadjusted trough concentrations. Variants in the genes PPARA, POR and CYP3A4 have recently been shown to influence tacrolimus metabolism. Furthermore, pharmacokinetic interaction between corticosteroid treatment and tacrolimus has been shown. In the present study, we investigated a potential association between $C Y P 3 A 5 * 3$, PPARA c. 209-1003G $>$ A, POR $* 28$ and CYP3A4*22 and
\end{abstract}

Mads Juul Madsen and Troels K. Bergmann contributed equally to the writing of this article.

Electronic supplementary material The online version of this article (doi:10.1007/s40268-017-0177-9) contains supplementary material, which is available to authorized users.

Troels K. Bergmann

tbergmann@health.sdu.dk

1 Department of Nephrology, Odense University Hospital, J B WinslowsVej 19, 5000 Odense C, Denmark

2 Department of Clinical Chemistry and Pharmacology, Odense University Hospital, Odense, Denmark

3 Hospital Pharmacy, Hospital of South West Denmark, Esbjerg, Denmark

4 Department of Clinical Pharmacology and Pharmacy, University of Southern Denmark, Odense, Denmark dose-adjusted tacrolimus trough concentrations in a primarily corticosteroid-free ( $>85 \%$ ) population of Danish pediatric and adult kidney transplant recipients.

Methods Seventy-two patients receiving treatment with oral tacrolimus were genotyped using real-time polymerase chain reaction and Primer-Probe Detection. Tacrolimus trough concentrations, corresponding doses and covariates were retrospectively collected from the patients' medical charts.

Results It was confirmed that $C Y P 3 A 5 * 1$ wild-type carriers had lower median dose-adjusted tacrolimus trough concentrations compared with noncarriers. Adults had 56 and $77 \%$ lower trough concentrations at 6 weeks $(p=0.0003)$ and 1 year, respectively $(p<0.0017)$, and, similarly, children had 65 and $39 \%$ lower median concentrations, with $p$ values of 0.006 and 0.011 , respectively. No association was found for PPARA c.209-1003G $>$ A, POR*28, or $C Y P 3 A 4 * 22$. An association between the PPARA c.209$1003 \mathrm{G}>\mathrm{A}$ genotype and an increased number of infections with cytomegalovirus (CMV) within the first year was identified $(p<0.05)$. Only $29 \%$ of trough concentrations measured between 2 and 12 weeks post-transplantation were on target.

Conclusion This study shows that the known association of the CYP3A5 genotype with tacrolimus dose-adjusted trough concentrations has the same impact in a corticosteroid-sparse population. The association between PPARA variance and infections with CMV will need further investigation. 


\section{Key Points}

Pediatric and adult cytochrome P450 (CYP) 3A5 expressers need a higher dose of tacrolimus compared with nonexpressers.

Corticosteroid avoidance does not affect the wellknown lower dose-adjusted trough concentrations among adult and pediatric CYP3A5 expressers compared with nonexpressers.

No association between $C Y P 3 A 4 * 22$, PPARA c.209$1003 \mathrm{G}>\mathrm{A}$ and $P O R * 28$ and tacrolimus doseadjusted trough concentrations was identified.

The PPARA variant allele was associated with an increased number of cytomegalovirus infections.

Only $29 \%$ of tacrolimus measurements were on target in weeks 2-12.

\section{Introduction}

Since the beginning of the 1980 s, the calcineurin inhibitors (CNIs) cyclosporine and tacrolimus have been essential for immunosuppression in solid organ transplantation. They both inhibit the calcineurin phosphatase activity, which results in reduced production of interleukin (IL)-2. Their introduction has led to considerable improvement in graft survival rates, and it has been shown that tacrolimus is related to a reduced risk of rejection [1]. Tacrolimus was first marketed in 1994 and has since then replaced cyclosporine as standard of care. The half-life of tacrolimus is 6-21 h and bioavailability is $25 \%$, but with great interindividual variation $[2,3]$. Tacrolimus is metabolized by cytochrome P450 (CYP) 3A4 and CYP3A5, and is a substrate for the efflux transporter P-glycoprotein. Tacrolimus exposure is typically managed by therapeutic drug monitoring (TDM) using trough concentration $\left(\mathrm{C}_{0}\right)$ order to ensure concentrations sufficiently high for adequate immunosuppression and, at the same time, sufficiently low to reduce the risk of adverse reactions, including nephrotoxicity.

Genetic factors are thought to play a significant role in the variability of the pharmacokinetics of tacrolimus. Research in this area might be of particular benefit in the initial phase, where tacrolimus steady-state is not reached and TDM is therefore of limited value. CYP $3 A 5^{*} I$ carrier status has thus been demonstrated to cause increased tacrolimus clearance with lower dose-adjusted trough concentration $\left(C_{0} / \mathrm{D}\right)$, whereas the most frequent variant of the gene CYP3A $5 * 3$ is associated with the lack of gene expression and the loss of functioning protein [4-9]. Recently, the CYP3A4*22 variant, with an allele frequency of 3-5\% in Caucasians, has also been suggested to affect tacrolimus [10, 11]; however, any impact of this variant remains to be demonstrated. Peroxisome proliferator-activated receptor-alpha (PPARA) is a receptor protein in the cell nucleus and is encoded by the gene of the same name. PPARA regulates genes involved in the transport, binding, and activation of fatty acids, including CYP3A. The variants c.209-1003G $>$ A (rs4253728, allele frequency $18-30 \%$ in Caucasians) and c. $208+3819 \mathrm{~A}>\mathrm{G}$ (rs 4823613 , allele frequency $20-30 \%$ in Caucasians) have thus been reported to explain up to $8-9 \%$ of variability in the hepatic portion of CYP3A activity [12]. PPARA variants could therefore theoretically affect tacrolimus dose requirements. CYP oxidoreductase (POR) is a protein with electron donor capacity important for the microsomal CYP system [13], thereby possibly influencing the activity of CYP3A. The most common variant of the POR gene is the POR*28 allele (rs1057868, allele frequency $30 \%$ in Caucasians). Carriers of this allele have been reported to have up to $15 \%$ lower tacrolimus $\mathrm{C}_{0} / \mathrm{D}$ in one study [7], but no effect in others [14, 15].

Progress in this field is evident, as demonstrated by the guideline recently published by the Clinical Pharmacogenetics Implementation Consortium (CPIC) [16]. CYP3A5 genotyping is not routinely recommended, but dose adjustments are recommended in cases where the CYP3A5 genotype is already known. Progress is largely based on studies that include transplant recipients concomitantly treated with corticosteroids. Corticosteroids have been shown to interact with tacrolimus concentration/dose ratios, possibly by enzyme-specific induction of CYP3A $[17,18]$. We therefore found it relevant and convenient to conduct this study at our institution, which has a long tradition of offering corticosteroid-free transplantation.

The aim of this retrospective study was to assess the effects of the CYP3A5*3, PPARA c. 209-1003G $>$ A, POR $* 28$ and CYP3A $4 * 22$ alleles on tacrolimus $\mathrm{C}_{0} / \mathrm{D}$, early rejection, and infection in a corticosteroid-sparse kidney transplant patient population consisting of both children and adults. We hypothesize that carriers of CYP3A5*3, PPARA c.209$1003 \mathrm{G}>\mathrm{A}$ and CYP3A $4 * 22$ will have higher tacrolimus $\mathrm{C}_{0} / \mathrm{D}$, while carriers of $\mathrm{POR}^{*} 28$ will have lower tacrolimus $\mathrm{C}_{0} / \mathrm{D}$. Furthermore, if the immunosuppression is affected by genotype, a significant difference in the number of infections and rejections between genotypes might be present.

\section{Patients and Methods}

\subsection{Patients and Recruiting}

We recruited pediatric and adult renal transplant patients from the Department of Nephrology, Odense University 
Hospital, Odense, Denmark, who were treated with tacrolimus twice daily. Patients or their legal guardian provided both written and oral consent to participate in the study. The study adhered to the Declaration of Helsinki and was approved by the Regional Ethics Committee (VEK \#S20140169). Blood samples for genotyping were initially collected from blood that was left from routine blood sampling that was part of planned outpatient clinic visits; however, the procedure proved inefficient and the protocol was amended to also include transplanted patients admitted to the ward. Blood was stored at $-20{ }^{\circ} \mathrm{C}$ within $24 \mathrm{~h}$ of collection.

\subsection{Data Collection}

Date of transplantation, donor status, height, weight, and other characterizations of the patients were extracted from the medical charts. This also included biochemical results and blood tacrolimus trough concentrations, as well as medication history. Tacrolimus was analyzed using an immunoassay at the hospital central laboratory as part of routine care. Concurrent medication was screened for the following CYP3A modulators: HIV antivirals, barbiturates, carbamazepine, enzalutamide, modafinil, oxcarbazepine, phenytoin, pioglitazone, rifabutin, rifampin, troglitazone, clarithromycin, itraconazole, ketoconazole, nefazodone, suboxone, telithromycin, aprepitant, erythromycin, fluconazole, verapamil, diltiazem, and cimetidine. Early graft rejections were defined as any biopsy-proven rejections within 1 year of transplantation, and tacrolimus blood concentrations were determined at the central hospital laboratory as part of routine patient care. We defined early and late tacrolimus exposure as the blood concentration trough value measured exactly by 6 and 52 weeks after transplantation, respectively. If no tacrolimus concentration had been taken that day, the nearest available value was used. Furthermore, if no concentration was available on the date \pm 10 days for early exposure, and \pm 20 days for late exposure, it was recorded as missing. Trough concentrations were classified as being either under, on, or over target for the relevant interval after transplantation, with reference to the current department guideline (see Online Resource Table S1).

Additionally, Epstein-Barr virus (EBV), and cytomegalovirus (CMV) pretransplant serology status was recorded, along with the number of infections within the first year post-transplantation. An episode of infection was defined as at least two consecutive measurements of $>1000$ viral DNA copies in blood samples (using polymerase chain reaction [PCR]). If a patient had a negative blood test while receiving antiviral treatment, but then received positive results when the antiviral treatment was discontinued, this was considered to be the same episode of infection.
Separate episodes of infection were defined to require the patient to have a period of 3 months with negative results in-between positive results, while not receiving antiviral treatment for that period.

\subsection{DNA Analysis}

DNA extraction was performed using the Maxwell ${ }^{\circledR} 16$ Promega and Maxwell ${ }^{\circledR} 16$ Blood DNA Purification Kit. Briefly, the blood was treated with proteinase $\mathrm{K}$ and lysis buffer, and kept at $56{ }^{\circ} \mathrm{C}$ to lessen the amount of protein in the blood samples; however, DNA extraction proved most successful by omitting the proteinase K. Genotyping was performed using real-time PCR with Applied Biosystems ${ }^{\circledR}$ StepOnePlus, using StepOne Software v2.3 and MicroAmp Fast 96-Well Reaction Plates with TaqMan ${ }^{\circledR}$ predesigned commercial genotyping assays. Genotype calling is semi-automatic. The specific assays used were rs776746 (C_26201809_30) for CYP3A5*3, rs4253728 (C_31052401_10) for PPARA c-209-1003G $>$ A, rs 1057868 (C_8890131_30) for POR*28, and rs35599367 (C_59013445_10) for CYP3A4*22.

\subsection{Statistical Analyses}

The effect of genotype on tacrolimus was assessed by comparing steady-state tacrolimus trough concentration corrected for dose $\left(\mathrm{C}_{0} / \mathrm{D}\right)$ across groups; steady-state was assumed after 5 days of constant dosing. Analyses were performed using STATA/IC14 (StataCorp LP, College Station, TX, USA), and associations between tacrolimus $\mathrm{C}_{0} / \mathrm{D}$ and variant genotypes and covariates were assessed using nonparametric analyses (Wilcoxon rank-sum test). Patients with rare homozygous genotypes were pooled with the heterozygous patients. No formal power calculation was performed prior to the study; however, similarly sized studies have previously demonstrated an impact of CYP3A5 genotype on tacrolimus trough concentrations in corticosteroid-treated populations. A $p$ value $<0.05$ was considered indicative of statistical significance.

\section{Results}

\subsection{Patients}

A total of 84 patients were initially included, however 12 were later excluded-two because they were treated with cyclosporine, and ten because data were not available from their medical charts. In total, 72 patients were eligible for analysis (see Table 1 for the demographic characteristics of both children and adults). No patients used any of the listed CYP3A modulators. Sex, age at transplantation, body mass index, height, weight, donor status, and smoking status did 
Table 1 Demographic data of children (defined as $<18$ years of age at the time of transplantation) and adults

\begin{tabular}{lll}
\hline Demographic & Adults $(n=52)$ & Children $(n=20)$ \\
\hline Male/female $(n)$ & $30 / 22$ & $12 / 8$ \\
Age at transplantation, years [median (range)] & $52(22-71)$ & $9(1-16)$ \\
Height 6 weeks after transplantation, cm [median (range)] & $171(149-191)$ & $127(81-174)$ \\
Weight 6 weeks after transplantation, kg [median (range)] & $77(37-117)$ & $24(11-48)$ \\
Living donor $(n)$ & 28 & 8 \\
Corticosteroids at 6 weeks (\%) & 15 & 10 \\
Mycophenolate mofetil at 6 weeks (\%) & 89 & 86 \\
Corticosteroids at 1 year (\%) & 16 & 0 \\
Mycophenolate mofetil at 1 year (\%) & 100 & 100 \\
Rejections within the first year ${ }^{\mathrm{a}}(n)$ & 4 & 0 \\
$\mathrm{CMV}^{\mathrm{b}}$ infections $(n)$ & 11 & 4 \\
EBV ${ }^{\mathrm{b}}$ infections $(n)$ & 2 & 7 \\
BKV ${ }^{\mathrm{b}}$ infections $(n)$ & 3 & 1 \\
\hline$C M V$ cytomegalovirus, $E B V$ Epstein-Barr virus, $B K V$ BK virus & \\
a Data available for 64 patients, respectively & & \\
b Data available for 61 patients, respectively &
\end{tabular}

not significantly correlate to tacrolimus $\mathrm{C}_{0} / \mathrm{D}$ and were therefore excluded from further analyses.

\subsection{Genotypes and Tacrolimus Dose-Adjusted Trough Concentrations}

Genotyping was carried out in duplicate. The results were consistent for all patients and for all genotypes, except for one patient where a third analysis of CYP3A5 was carried out. Genotype and allele frequencies of all investigated variants are shown in Table 2. All gene variants were in Hardy-Weinberg equilibrium. The group of combined CYP3A5*1 allele carriers had $63 \%$ lower median tacrolimus $\mathrm{C}_{0} / \mathrm{D}$ compared with homozygote carriers of the CYP3A $5 * 3$ allele at 6 weeks post-transplantation (1.33 vs. $3.56 \mathrm{ng} / \mathrm{ml} / \mathrm{mg}, p<0.0001)$. The statistically significant difference remained in a sensitivity test without corticosteroid-using patients (data not shown). For 1 year posttransplantation, CYP3A5*1 carriers had $62 \%$ lower median tacrolimus $\mathrm{C}_{0} / \mathrm{D}$ compared with homozygote carriers of the CYP3A5*3 allele $(1.34$ vs. $3.53 \mathrm{ng} / \mathrm{ml} / \mathrm{mg}, p=0.0001)$. Again, the significant difference remained after removing patients using corticosteroids. Analyses of children and adults separately showed a similar impact of CYP3A $5 * 1$ (see Tables 3 and 4 and Fig. 1). Stratified for the CYP3A5 genotype, no significant difference in $\mathrm{C}_{0} / \mathrm{D}$ was observed between children and adults.

Neither PPARA c.209-1003G $>$ A nor POR $* 28$ showed any association with tacrolimus $C_{0} / D$ at 6 weeks or 1 year following transplantation. As with CYP3A5, carriers of the investigated variant alleles (G/A and A/A for PPARA; *1/ $* 28$ and $* 28 / * 28$ for POR) were grouped together and
Table 2 Genotypes of 72 adult and pediatric kidney transplant recipients

\begin{tabular}{|c|c|}
\hline & $N(\%)$ \\
\hline \multicolumn{2}{|l|}{ CYP3A5 } \\
\hline$* 1 / * 1$ & $1(1)$ \\
\hline$* 1 / * 3$ & $11(15)$ \\
\hline$* 3 / * 3$ & $60(83)$ \\
\hline \multicolumn{2}{|l|}{ PARA } \\
\hline $\mathrm{G} / \mathrm{G}$ & $38(53)$ \\
\hline G/A & $26(36)$ \\
\hline $\mathrm{A} / \mathrm{A}$ & $8(11)$ \\
\hline \multicolumn{2}{|l|}{ CYP3A4 } \\
\hline$* 1 / * 1$ & $68(94)$ \\
\hline$* 1 / * 22$ & $4(6)$ \\
\hline \multicolumn{2}{|l|}{ OR } \\
\hline$* 1 / * 1$ & $43(60)$ \\
\hline$* 1 / * 28$ & $24(33)$ \\
\hline$* 28 / * 28$ & $5(7)$ \\
\hline \multicolumn{2}{|c|}{ CYP cytochrome $\mathrm{P} 450$, PPARA } \\
\hline $\begin{array}{c}\text { chron } \\
\text { oredu }\end{array}$ & $\mathrm{P} 450$ \\
\hline
\end{tabular}

compared to patients who were homozygous for the nonvariant alleles to assess the potential effect of carrying at least one variant, but no differences were detected. Additionally, it was assessed whether the presence of a POR $* 28$ allele among CYP3A5* 1 carriers would show an effect on tacrolimus $\mathrm{C}_{0} / \mathrm{D}$, but no significant effect was found. Interestingly, patients heterozygous for the CYP3A $4 * 22$ allele (adults plus children) had $177 \%$ higher median tacrolimus $\mathrm{C}_{0} / \mathrm{D}$ compared with homozygote wild-type 
Table 3 Tacrolimus dose-adjusted trough concentrations in adults and children across genotypes 6 weeks after kidney transplantation

\begin{tabular}{|c|c|c|c|}
\hline Genotype & $\begin{array}{l}\text { Tacrolimus trough }\left(\mathrm{C}_{0} / \mathrm{D} ; \mathrm{ng} / \mathrm{mL} / \mathrm{mg}\right) \\
\text { [median (range)] }\end{array}$ & No. of patients & $\begin{array}{l}p \text { value (Wilcoxon } \\
\text { rank-sum test) }\end{array}$ \\
\hline \multicolumn{4}{|l|}{ Adults } \\
\hline \multicolumn{4}{|l|}{ CYP3A5 } \\
\hline$* 1 / * 1$ and $* 1 / * 3$ & $1.31(0.89-3.94)$ & 8 & \\
\hline$* 3 / * 3$ & $3.0(1.13-14.2)$ & 44 & 0.0003 \\
\hline \multicolumn{4}{|l|}{ PPARA } \\
\hline $\mathrm{G} / \mathrm{G}$ & $2.76(1.13-12.9)$ & 29 & \\
\hline $\mathrm{G} / \mathrm{A}+\mathrm{A} / \mathrm{A}$ & $2.94(0.89-14.2)$ & 23 & 0.73 \\
\hline \multicolumn{4}{|l|}{ POR } \\
\hline$* 1 / * 1$ & $3.94(0.89-14.2)$ & 27 & \\
\hline$* 1 / * 28+* 28 / * 28$ & $2.35(1.13-12.9)$ & 25 & 0.36 \\
\hline \multicolumn{4}{|l|}{ CYP3A4 } \\
\hline$* 1 / * 1$ & $2.76(0.89-14.2)$ & 49 & \\
\hline$* 1 / * 22$ & $5.15(2.76-12.6)$ & 3 & 0.24 \\
\hline \multicolumn{4}{|l|}{ Children } \\
\hline \multicolumn{4}{|l|}{ CYP3A5 } \\
\hline$* 1 / * 1$ and $* 1 / * 3$ & $1.42(1.08-1.85)$ & 4 & \\
\hline$* 3 / * 3$ & $4.01(1.24-30.0)$ & 16 & 0.0061 \\
\hline \multicolumn{4}{|l|}{ PPARA } \\
\hline $\mathrm{G} / \mathrm{G}$ & $3.96(1.33-10.1)$ & 9 & \\
\hline $\mathrm{G} / \mathrm{A}+\mathrm{A} / \mathrm{A}$ & $2.32(1.08-30.0)$ & 11 & 0.85 \\
\hline \multicolumn{4}{|l|}{ POR } \\
\hline$* 1 / * 1$ & $3.13(1.08-30)$ & 16 & \\
\hline$* 1 / * 28+* 28 / * 28$ & $2.91(1.24-17.2)$ & 4 & 0.71 \\
\hline \multicolumn{4}{|l|}{ CYP3A4 } \\
\hline$* 1 / * 1$ & $2.73(1.08-30)$ & 19 & \\
\hline$* 1 / * 22$ & 10.1 & 1 & NA \\
\hline
\end{tabular}

CYP cytochrome P450, NA not applicable, POR cytochrome $\mathrm{P} 450$ oxidoreductase, PPARA peroxisome proliferator-activated receptor-alpha

carriers at 6 weeks post-transplantation, but the result was not statistically significant $(p=0.10)$. No trend was detected at 1 year post-transplantation.

A total of 648 tacrolimus concentrations were registered between 2 and 12 weeks after transplantation. No significant difference was observed between any of the investigated genotypes and the percentage distribution of tacrolimus trough concentrations under, on, or over designated targets (Fig. 2). The overall distribution was 167 (26\%) under target, $186(29 \%)$ on target, and 295 (46\%) over target, with no difference between children and adults.

\subsection{Infection and Graft Rejection}

Overall, 61 patients had data available regarding virus infections within the first year following transplantation (Table 1). No association between CYP3A5*3, CYP3A4*22, or $\mathrm{POR} * 28$ variant alleles and infection within the first year following transplantation was found; however, a potential association between the PPARA c.209-1003G $>$ A variant allele and the number of CMV infections was identified. Carriers of the variant allele also more frequently had at least one episode of CMV infection ( $p$ value $<0.05$, Fishers exact test). Acute biopsy-proven rejection within the first year was 6.3\% $(n=64$, four adults). No association was found between variant alleles and the number of rejections within the first year.

\section{Discussion}

We assessed the effect of sequence variants in CYP3A5, CYP3A4, PPARA, and POR on tacrolimus trough concentrations in a mostly $(>85 \%)$ corticosteroid-free population of adult and pediatric kidney transplant patients. Carriers of the CYP3A5*1 allele had between $39 \%$ and $77 \%$ lower median tacrolimus dose-adjusted trough concentrations $\left(\mathrm{C}_{0} / \mathrm{D}\right)$ than noncarriers $(p \leq 0.01)$. This study 
Table 4 Tacrolimus dose-adjusted trough concentrations in adults and children across genotypes 1 year after kidney transplantation

\begin{tabular}{|c|c|c|c|}
\hline Genotype & $\begin{array}{l}\text { Tacrolimus trough } \\
\left(\mathrm{C}_{0} / \mathrm{D} ; \mathrm{ng} / \mathrm{mL} / \mathrm{mg}\right) \\
{[\text { median (range) }}\end{array}$ & $\begin{array}{l}\text { No. of } \\
\text { patients }\end{array}$ & $\begin{array}{l}p \text { value } \\
\text { (Wilcoxon } \\
\text { rank-sum test) }\end{array}$ \\
\hline \multicolumn{4}{|l|}{ Adults } \\
\hline \multicolumn{4}{|l|}{ CYP3A5 } \\
\hline$* 1 / * 1$ and $* 1 / * 3$ & $1.03(0.25-3.27)$ & 6 & \\
\hline$* 3 / * 3$ & $4.53(0.88-11.4)$ & 31 & 0.0017 \\
\hline \multicolumn{4}{|l|}{ PPARA } \\
\hline $\mathrm{G} / \mathrm{G}$ & $3.4(0.25-7.5)$ & 20 & \\
\hline $\mathrm{G} / \mathrm{A}+\mathrm{A} / \mathrm{A}$ & $3.2(0.74-11.4)$ & 17 & 0.55 \\
\hline \multicolumn{4}{|l|}{ POR } \\
\hline$* 1 / * 1$ & $3.53(0.74-11.4)$ & 19 & \\
\hline$* 1 / * 28+* 28 / * 28$ & $3.23(0.25-7.5)$ & 18 & 0.94 \\
\hline \multicolumn{4}{|l|}{ CYP3A4 } \\
\hline$* 1 / * 1$ & $3.23(0.88-11.4)$ & 36 & \\
\hline$* 1 / * 22$ & 3.53 & 1 & NA \\
\hline \multicolumn{4}{|l|}{ Children } \\
\hline \multicolumn{4}{|l|}{ CYP3A5 } \\
\hline$* 1 / * 1$ and $* 1 / * 3$ & $1.69(0.60-2.0)$ & 4 & \\
\hline$* 3 / * 3$ & $2.79(1.73-5.4)$ & 14 & 0.0107 \\
\hline \multicolumn{4}{|l|}{ PPARA } \\
\hline $\mathrm{G} / \mathrm{G}$ & $2.2(1.48-5.0)$ & 9 & \\
\hline $\mathrm{G} / \mathrm{A}+\mathrm{A} / \mathrm{A}$ & $2.3(0.6-5.4)$ & 9 & 0.83 \\
\hline \multicolumn{4}{|l|}{ POR } \\
\hline$* 1 / * 1$ & $2.2(0.6-5.0)$ & 15 & \\
\hline$* 1 / * 28+* 28 / * 28$ & $2.32(2-5.4)$ & 3 & 0.41 \\
\hline \multicolumn{4}{|l|}{ CYP3A4 } \\
\hline$* 1 / * 1$ & $2.2(0.6-5.4)$ & 17 & \\
\hline$* 1 / * 22$ & 3.5 & 1 & NA \\
\hline
\end{tabular}

CYP cytochrome P450, NA not applicable, POR cytochrome P450 oxidoreductase, PPARA peroxisome proliferator-activated receptor-alpha

confirms the importance of CYP3A5 gene variants on tacrolimus trough concentrations previously demonstrated [4-8]; however, with the present study we show that the effect of CYP3A5 genotype on tacrolimus is also present in a mostly corticosteroid-free population, which, to our knowledge, has not been demonstrated before. Thervet et al. [19] reported that patients who received a genotypespecific tacrolimus dose obtained target concentrations faster than control patients. Current guidelines do not recommend pre-emptive genotyping; however, dosing adjustments are recommended in cases where the genotype is known already [16].

No effect of PPARA c.209-1003G $>$ A on tacrolimus $C_{0} /$ $\mathrm{D}$ was found in this study, which is in accordance with the studies by Kurzawski et al. [14] and Bruckmueller et al. [15], but in contrast to Lunde et al. [7], who reported $19 \%$ higher tacrolimus $\mathrm{C}_{0} / \mathrm{D}$ among PPARA variant carriers in a study with 123 Norwegian kidney transplant patients. These mixed results warrant further investigation.
Furthermore, this study found no effect of the investigated POR genotype variants on tacrolimus $\mathrm{C}_{0} / \mathrm{D}$, which is in contrast to Lunde et al. [7], who found that patients with POR $* 28$ variant alleles showed $15 \%$ lower tacrolimus $\mathrm{C}_{0} /$ D. Several other studies found that $\mathrm{POR} * 28$ polymorphisms significantly lowered tacrolimus $\mathrm{C}_{0} / \mathrm{D}$ among CYP3A5*1 carriers $[4,20]$, however this association was not shown by Lunde et al. In addition, we failed to find any association between $\mathrm{POR} * 28+\mathrm{CYP} 3 \mathrm{~A} 5 * 1$ and tacrolimus $\mathrm{C}_{0} / \mathrm{D}$; however, this could be explained by the low number of CYP3A $5 * 1$ allele carriers $(n=12)$ in this study. No significant effect of the CYP3A $4 * 22$ variant allele was found, although it might be argued that a trend for higher $\mathrm{C}_{0} / \mathrm{D}$ might be possible (177\% increase, $\left.p=0.10\right)$. This result might be limited by the fact that only four patients carried the CYP3A4*22 allele. Other studies found no effect of CYP3A $4 * 22$ polymorphism [7, 15, 21], while one study found that significantly less patients carrying a CYP3A $4 * 22$ allele reached target concentrations of tacrolimus within the first 10 days following transplantation [10]. Certainly, this association demands further elucidation.

In an exploratory analysis of data from 61 patients with available infection data, PPARA c.209-1003G $>$ A was found to be significantly associated with the number of CMV infections within the first year following transplantation. For the other genes, no other association was found between genotype and the number of infections with CMV, EBV or BKV within the first year. Since PPARA was not associated with high tacrolimus concentrations, over-immunosuppression cannot explain an increased risk of infections. Moreover, if such an effect was present, carriers of the wild-type CYP3A5 variant would also have an increased risk of infections, but this was not observed. It could be speculated that PPARA possibly influences drug exposure at the tissue level without measurable impact on plasma kinetics, but the possibility of a spurious result must also be considered.

No association between genotype and the distribution of tacrolimus measurements within weeks 2-12 was found, which was somewhat surprising as we expected carriers of the CYP3A $5 * 1$ allele to have more measurements below target relative to homozygous CYP $3 \mathrm{~A} 5 * 3$ carriers. However, there is certainly room for improvement, with less than one-third of measurements actually being on target. This might suggest that genotype-adjusted dosing in the initial phase could be a potential improvement. The small sample size and retrospective design might have limited the investigated associations across this study. CYP3A5* 1 and CYP3A4*22 allele frequencies in Caucasians are quite low and could influence the results.

This study used retrospectively collected tacrolimus trough concentrations only. Drug monitoring using only 
Fig. 1 Dose-adjusted tacrolimus trough concentrations $\left(\mathrm{C}_{0} / \mathrm{D}\right)$ in adults 6 weeks after kidney transplantation. Boxes delimit the upper and lower quartile and median, the outliers are $>1.5$ times the interquartile range from the quartiles, and the whiskers mark the extreme values that are not outliers. CYP cytochrome P450, POR cytochrome $\mathrm{P} 450$ oxidoreductase, PPARA peroxisome proliferatoractivated receptor-alpha
Fig. 2 Distribution of tacrolimus trough concentrations under target, on target, or above target 2-12 weeks after kidney transplantation across the CYP3A5 genotype. CYP cytochrome $\mathrm{P} 450$
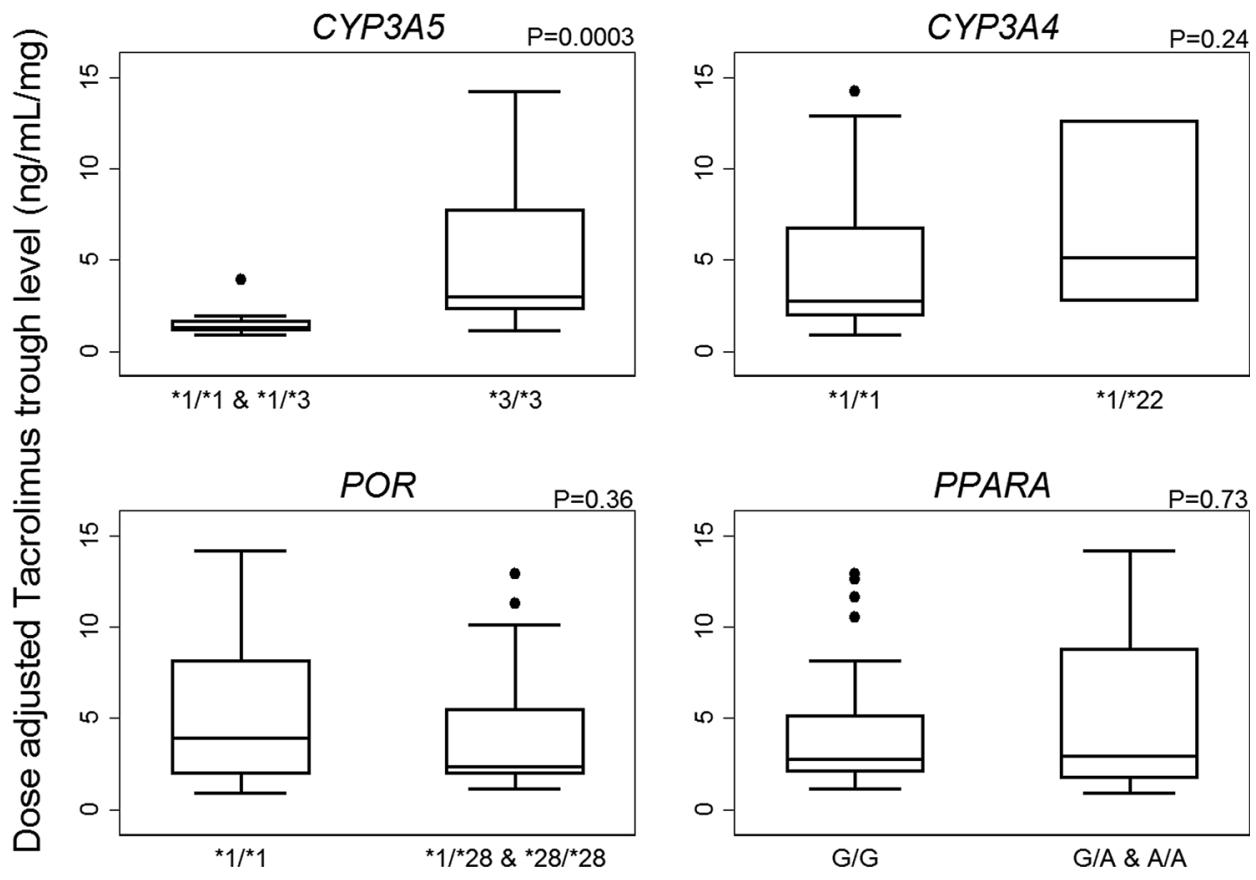

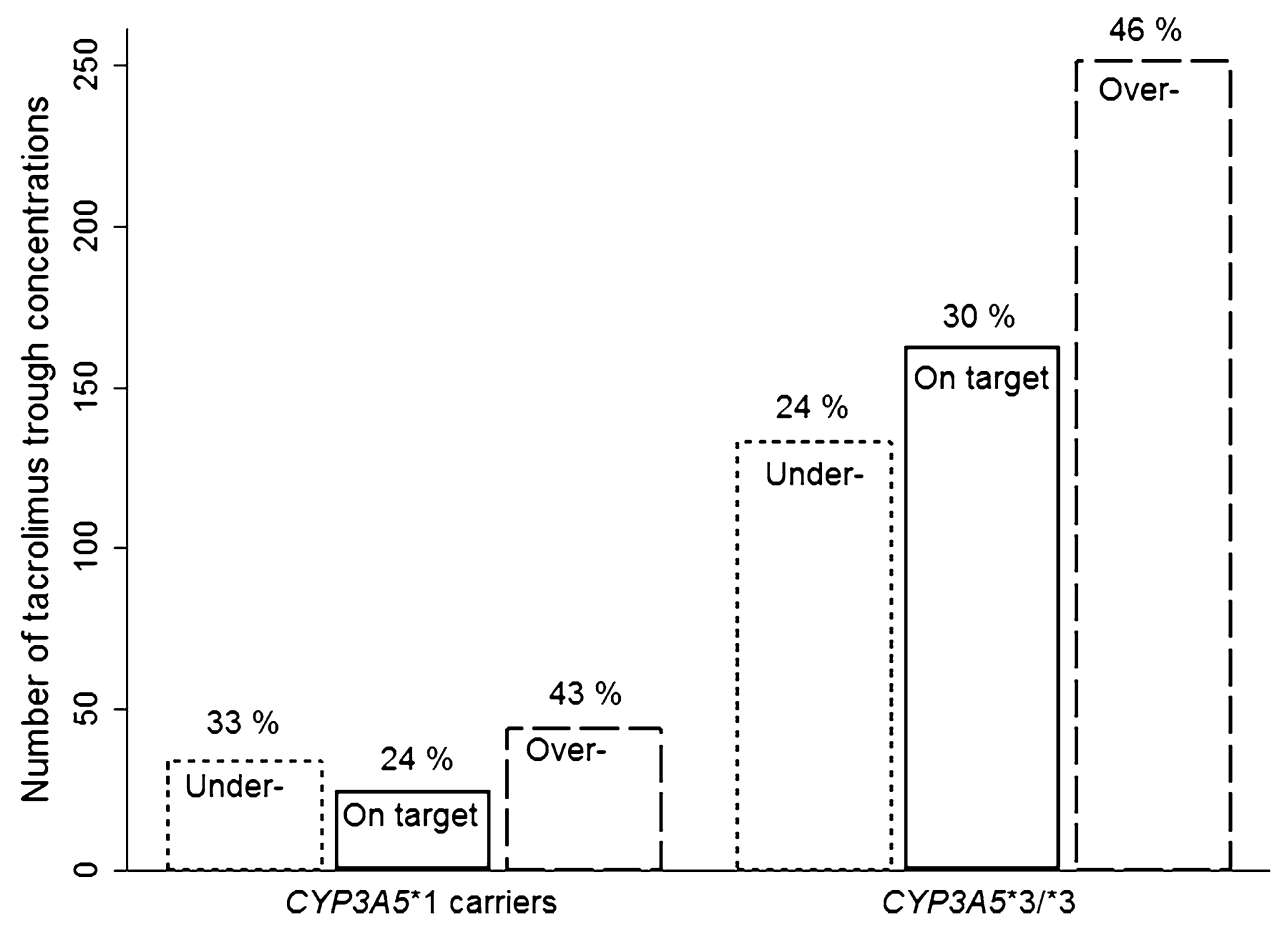

these concentrations is not ideal because correlation with area under the concentration-time curve (AUC) can be elusive, and treatment failures also occur within targeted tacrolimus concentration ranges. Future pharmacogenetic studies may want to prioritize the collection of full AUC data if possible. This study was designed to assess the influence of genotypes separately. A more powerful study might also have included analyses of combinations of genotypes. Another limitation to this study is the lack of formal registration of episodes of diarrhea, which is welldocumented to influence tacrolimus absorption, as well as, therefore, trough concentrations. 


\section{Conclusion}

This study confirms the impact of CYP3A5 variant alleles on tacrolimus dose-adjusted trough concentrations in a largely corticosteroid-free population. We showed that less than one-third of the measured trough concentrations of tacrolimus were on target between weeks 2 and 12 after transplantation, independent of genotype. No other effect of genotype on tacrolimus dose-adjusted trough concentrations was found. The potential effect of PPARA c.209$1003 \mathrm{G}>\mathrm{A}$ on the number of CMV infections within the first year will need further prospective study with a larger sample size.

\section{Compliance with Ethical Standards}

Conflict of interest Mads Juul Madsen, Troels K. Bergmann, Kim Brøsen, and Helle Charlotte Thiesson have no conflict of interests to declare pertaining to this study.

Funding Funding for this study was supported by the Jakob and Olga Madsens fund.

Approval of Ethics and Data Collection This study was approved by the Research Ethics Committee S-20140169 and the Danish Data Protection Agency jr.nr. 15/23484.

Open Access This article is distributed under the terms of the Creative Commons Attribution-NonCommercial 4.0 International License (http://creativecommons.org/licenses/by-nc/4.0/), which permits any noncommercial use, distribution, and reproduction in any medium, provided you give appropriate credit to the original author(s) and the source, provide a link to the Creative Commons license, and indicate if changes were made.

\section{References}

1. Ekberg H, Tedesco-Silva H, Demirbas A, Vitko S, Nashan B, Gurkan A, et al. Reduced exposure to calcineurin inhibitors in renal transplantation. N Engl J Med. 2007;357(25):2562-75.

2. Immunfarmakologi Carstens J. In: Brøsen K, Simonsen U, Kampmann JP, Thirstrup S, editors. Basal og Klinisk Farmakologi. 5th ed. Copenhagen: FADL's Forlag; 2014. p. 224-41.

3. Staatz CE, Tett SE. Clinical pharmacokinetics and pharmacodynamics of tacrolimus in solid organ transplantation. Clin Pharmacokinet. 2004;43(10):623-53.

4. Birdwell K. Role of pharmacogenomics in dialysis and transplantation. Curr Opin Nephrol Hypertens. 2014;23(6):570-7.

5. Yaowakulpatana K, Vadcharavivad S, Ingsathit A, Areepium N, Kantachuvesiri S, Phakdeekitcharoen B, et al. Impact of CYP3A5 polymorphism on trough concentrations and outcomes of tacrolimus minimization during the early period after kidney transplantation. Eur J Clin Pharmacol. 2016;72(3):277-83.

6. Hesselink DA, van Schaik RH, van der Heiden IP, van der Werf M, Smak PJH, Lindemans GJ. Genetic polymorphisms of the CYP3A4, CYP3A5, and MDR-1 genes and pharmacokinetics of the calcineurin inhibitors cyclosporine and tacrolimus. Clin Pharmacol Ther. 2003;74(3):245-54.

7. Lunde I, Bremer S, Midtvedt K, Mohebi B, Dahl M, Bergan S, et al. The influence of CYP3A, PPARA, and POR genetic variants on the pharmacokinetics of tacrolimus and cyclosporine in renal transplant recipients. Eur J Clin Pharmacol. 2014;70(6):685-93.

8. Cusinato DA, Lacchini R, Romao EA, Moyses-Neto M, Coelho EB. Relationship of CYP3A5 genotype and ABCB1 diplotype to tacrolimus disposition in Brazilian kidney transplant patients. $\mathrm{Br}$ J Clin Pharmacol. 2014;78(2):364-72.

9. Dai Y, Hebert MF, Isoherranen N, Davis CL, Marsh C, Shen DD, et al. Effect of CYP3A5 polymorphism on tacrolimus metabolic clearance in vitro. Drug Metab Dispos. 2006;34(5):836-47.

10. Pallet N, Jannot AS, El Bahri M, Etienne I, Buchler M, de Ligny $\mathrm{BH}$, et al. Kidney transplant recipients carrying the CYP3A4*22 allelic variant have reduced tacrolimus clearance and often reach supratherapeutic tacrolimus concentrations. Am J Transplant. 2015;15(3):800-5.

11. de Jonge H, Elens L, de Loor H, van Schaik RH, Kuypers DR. The CYP3A4*22 C>T single nucleotide polymorphism is associated with reduced midazolam and tacrolimus clearance in stable renal allograft recipients. Pharmacogenomics J. 2015;15(2):144-52.

12. Klein K, Thomas M, Winter S, Nussler AK, Niemi M, Schwab $\mathrm{M}$, et al. PPARA: a novel genetic determinant of CYP3A4 in vitro and in vivo. Clin Pharmacol Ther. 2012;91(6):1044-52.

13. Hubbard PA, Shen AL, Paschke R, Kasper CB, Kim JJ. NADPHcytochrome $\mathrm{P} 450$ oxidoreductase. Structural basis for hydride and electron transfer. J Biol Chem. 2001;276(31):29163-70.

14. Kurzawski M, Malinowski D, Dziewanowski K, Drozdzik M. Impact of PPARA and POR polymorphisms on tacrolimus pharmacokinetics and new-onset diabetes in kidney transplant recipients. Pharmacogenet Genom. 2014;24(8):397-400.

15. Bruckmueller H, Werk AN, Renders L, Feldkamp T, Tepel M, Borst $\mathrm{C}$, et al. Which genetic determinants should be considered for tacrolimus dose optimization in kidney transplantation? A combined analysis of genes affecting the CYP3A locus. Ther Drug Monit. 2015;37(3):288-95.

16. Birdwell KA, Decker B, Barbarino JM, Peterson JF, Stein CM, Sadee W, et al. Clinical Pharmacogenetics Implementation Consortium (CPIC) guidelines for CYP3A5 genotype and tacrolimus dosing. Clin Pharmacol Ther. 2015;98(1):19-24.

17. Anglicheau D, Flamant M, Schlageter MH, Martinez F, Cassinat $\mathrm{B}$, Beaune $\mathrm{P}$, et al. Pharmacokinetic interaction between corticosteroids and tacrolimus after renal transplantation. Nephrol Dial Transplant. 2003;18(11):2409-14.

18. Bergmann TK, Barraclough KA, Lee KJ, Staatz CE. Clinical pharmacokinetics and pharmacodynamics of prednisolone and prednisone in solid organ transplantation. Clin Pharmacokinet. 2012;51(11):711-41.

19. Thervet E, Loriot MA, Barbier S, Buchler M, Ficheux M, Choukroun $\mathrm{G}$, et al. Optimization of initial tacrolimus dose using pharmacogenetic testing. Clin Pharmacol Ther. 2010;87(6):721-6.

20. de Jonge H, Metalidis C, Naesens M, Lambrechts D, Kuypers DR. The P450 oxidoreductase $* 28$ SNP is associated with low initial tacrolimus exposure and increased dose requirements in CYP3A5-expressing renal recipients. Pharmacogenomics. 2011;12(9):1281-91.

21. Pulk RA, Schladt DS, Oetting WS, Guan W, Israni AK, Matas $\mathrm{AJ}$, et al. Multigene predictors of tacrolimus exposure in kidney transplant recipients. Pharmacogenomics. 2015;16(8):841-54. 